\title{
DEVELOPMENT OF AN ENVIRONMENT FRIENDLY METHOD TO REMOVE THI COLORED COMPONENTS FROM INDUSTFIAL WASTE WATER
}

\author{
Dinesh Pandithawidana \& K.R. Ranjith Mahanama \\ Department of Chemisty, University of Colombo
}

Nowadays, synthetic dye context is a vital component in the textile and dyeing industries. The garrient factories in the free trade zone that are discharging dyes and other coloured compourds into waterways pollute the environment. In this project, attempts were made to design an environment friendly methodology to degrade Azo dyes by means of Eco-efficient techniques. Optimum conditions were evaluated for the redox-degradation of the Azo dye: and some of the dyes that are used in garment industry. The fidelity of the proposed mechanism was confirmed by the spectroscopic and GC analyses. As a reducing agent, metallic iron has fulfilled all the requirements that are prescribed for green chemical concepts.

The results presented in this report clearly demonstrate that Anthroquinone-2-sulphonic acid is a powerful catalyst, capable of accelerating the reaction rate by orders of magnitude. The powdered form of charcoal amalgamated with metallic iron has facilitated as a better substrate to adsorb the dye component improving the contacts of reactant molecules with the catalyst and dye molecules. The experimental results revealed that $\mathrm{pH} 4$ is the optimum condition for the redox degradation of the dye, which is confirmed by electrochemical, and thermodynamic calculations. The elevation of the reaction temperature has accelerated the reaction by several orders of magnitude. To demonsirate the applications in real world a continuous flow reduction apparatus was designell and constructed. 